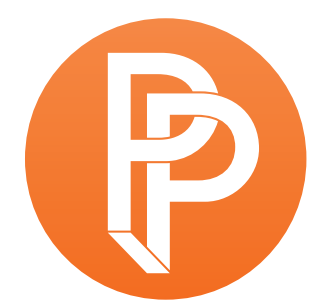

PERFORMANCE

PHILOSOPHY

\title{
WHAT IS REFUGEE?
}

\author{
WILL DADDARIO INDEPENDENT SCHOLAR, USA \\ JANHAVIDHAMANKAR VIENNA UNIVERSITY, AUSTRIA \\ MILTONLOAYZA SUNY OSWEGO, USA \\ JON MCKENZIE CORNELL UNIVERSITY, USA \\ YANA MEERZON UNIVERSITY OF OTTAWA, CANADA \\ TERO NAUHA UNIVERSITY OF THE ARTS HELSINKI, FINLAND \\ THERON SCHMIDT UNSW SYDNEY, AUSTRALIA \\ ANETA STOJNIĆ SINGIDUNUM UNIVERSITY, BELGRADE, SERBIA
}


For the 2017 meeting of Performance Studies international in Hamburg, Germany, the Performance and Philosophy Working Group convened a six-hour discussion on the figure of the refugee. Designed as a kind of "conference in reverse," the participants in the conversation did not arrive with anything specific to present but, rather, utilized the meeting in Hamburg to think collectively about the refugee and the conference theme of "Overflow." The plan was to perform this thinking as a mode of research and then compile our thoughts afterward, thereby inverting the typical conference format. Ultimately, the six-hour conversation left us with many questions, some of which were complete while others were mere fragments. In each of them, however, one can sense a distinct theme: the figure of the refugee challenges thought.

What is an appropriate art-philosophical response to the enforced homelessness of over 60 million people? Are we prepared to use the word "refugee" to name each of these people, or is the name itself a red herring that leads us down pre-paved discursive paths? Does the term "crisis" compound this problem? Would one million displaced individuals not constitute a crisis? How does one begin to think about these numbers, these global movements, these words we deploy to think the so-called refugee?

What follows is a curated, collective response to the set of questions (or fragments of questions) derived from our conference experiment. The questions reproduced here are selections from responses from various participants at the Hamburg event, including the named contributors to this piece as well as others who came in and out of the room over the six-hour duration. Delivered through mixed-media, the responses cover a vast range of territory, from the relation between refugees and global capitalism to the reign of bio- and necro-politics, from analytical philosophies of naming to continental philosophies of territorialized flows, and from conceptual mappings of interstitial space to concrete mappings of "refugee" movements across the globe.

How can performance philosophy conceptualize "crisis" in its methods and subjects of study? How is crisis organized, delivered and received in thought and performance? These are the questions we answer through both the form and content of our curated response. The form is one of arranged fragments that speak to the "trailing off" of thought that so frequently occurs when faced with "big ideas." Meanwhile, the content delivers multiple theses on the ways performance philosophy scholarship might grapple with the figure of the refugee, a figure that will surely dominate ethical discussions for years to come.

Ultimately, most of the epistemological work falls to you, the reader, whose role it is to assemble these fragments and provocations into a mode of action. You will find that this piece asserts itself less through traditional, academic argument and more through affective jolts. Please register these jolts, reflect on them, and see where they lead you.

Collectively authored by Will Daddario, Janhavi Dhamankar, Milton Loayza, Jon McKenzie, Yana Meerzon, Tero Nauha, Theron Schmidt, and Aneta Stojnić. 


\title{
How to distinguish
}

host refugee stranger

\begin{abstract}
A host determines a position for a refugee. A host itself is a position. A refugee is not looking for a host, but she is looking for a position for herself, which is different one from being a refugee. These are both identities that are unilateral positions. A stranger is what replaces the humanitarian Other. The Stranger is not a position, in other words it is not determined by the instance of humanity.
\end{abstract}

\section{(Preliminary response)}

A negative/pitiful connotation extends through the etymology of "refugee" in different languages. For example: Sharanaarthi in Hindi meaning one who prays/begs (for a place), Nirvaasit in Sanskrit meaning homeless or one who is uprooted from his homeland, Muhajir in Urdu meaning one who abandons or quits.

To analyse the etymology of "refugee" in English and to couple its meaning with "intensified flight" offers an interesting possibility viz. the same noun "flight" describes the act of the refugee on the one hand, who acts out of/takes flight due to lack of other options/choice. On the other hand, a bird's flight is used as a metaphor for freedom and for a situation with multiple possibilities and choices.

The following verse from a Bollywood song highlights this aspect.

Panchhee, nadiyaan, pawan ke jhonke

Koi sarhad naa inhe roke

Sarhadein insaanon ke liye hai

Socho, tumne aur maine,

Kya paaya insaan ho ke!

$$
\text { - Javed Akhtar }
$$

As far as birds, rivers and gusts of wind go,

There are no borders to stop their flow.

It's worth giving it a thought

What being human has wrought.

(My translation) 


\section{(Social/political context of the terms)}

Host is hospitality, social term. It inherently entails an action to extend hospitality, viz. food, shelter, (basic) comfort to an-other.

"Refugee" is a political term/concept, and this fact shapes its image in the social context. Hence, if the social image of the refugee is to change, in terms of how we interact with and view refugees, the political connotation and political language would have to change/ shift.

Stranger is an intersubjective term since one is a stranger to someone or something. Hence, it entails a relation to/ relatedness to something. Similarly, a host also entails an audience or a relation to someone or a group. But a host also carries a hierarchy within it i.e. the host is the giver or presenter. In contrast, a refugee is one at the lower step or other end of the hierarchy, i.e. the receiver.

If this notion and hierarchy of the giver and receiver roles can be interchanged or seen as shifting and reciprocating regularly, the refugee could become the giver sometimes, for example in some cultural aspects such as contributing to the food/cuisine of a place. However, for this too, the "host" needs to be able to shift his/her role (or the host country its role) and be able to receive. this would entail, not to discard everything brought in and offered by the refugees as a blanket rule.

Thus, can we look at the refugee as a unit/possibility of culture? Either the refugee needs to restore and reinvent his own culture in order to survive in the new land, or the refugee needs to imbibe the culture of the new land. ${ }^{1}$ This conception may help to build an image of the refugee as someone who carries richness within him/herself and can thereby offer possibilities to the new land/country.

\section{(Sense of entitlement vs. being done a favour to)}

As compared to each other, host, refugee and stranger would also differ in the sense of entitlement they carry. The host (citizen or country) is entitled to certain rights, privileges and is also, to an extent, the one who decides such entitlement, its terms, its processes. Refugee could yearn for (and earn) a sense of entitlement, depending on the proximity of the traumatic past and of "arriving" in another place/land/ country. However, in most cases, refugee views himself/herself and is also viewed by the state, society as someone who is being done a favour to. This implicitly means that refugee is not entitled to certain rights e.g. land, food, warmth, any kinds of basic needs as well as comfort (and even recreation). If the/a refugee receives any of these, it is a favour that the government or individual citizens extend to him. 


\section{(Types of Freedom)}

Joel Feinberg discusses varieties of freedom in the first chapter of his Social Philosophy (1973). I find 2 of these kinds of freedom useful to distinguish the host, refugee, stranger.

Actual freedom: freedom from certain These conceptualizations of freedom constraints. are in practice so loaded with ideas of culture, identity, nation, citizenship

Dispositional freedom: freedom to perform certain actions.

A host is "entitled" to actual and dispositional freedom. i.e. $s /$ he is free from constrains for instance of persecution and also free to act e.g. seek a job. Refugee, however, experiences a lack of both (or at least one) of these freedoms. Refugee is seldom free from persecution in etc. Is the refugee crisis evidence that these concepts which serve bio- and necro-politics (see Stojnić) need to be transformed or replaced by new ones (see Meerzon on cosmopolitanism and "naked life," and Nauha on " $X$ "), so we can think of a strategy to survive the crisis?!

his/her own country but also in the host country or the foreign land. In addition, refugee has no dispositional freedom which is hypothetical, e.g. if the refugee were to choose so, s/he would not be free to take up a job, or simply, live in the land of one's choice.

Examining the etymology of the word crisis in English, I came across the German term Torschlusspanik (for mid-life crisis), which literally means "shut-door-panic" or fear of being on the wrong side of a closing gate. I believe this describes exactly the situation of the refugee and therefore the "crisis." This fear or panic can be understood to stem from a threat to dispositional (or hypothetical) freedom. Along with the actual freedom (freedom from certain constraints), even the dispositional freedom (freedom to perform certain acts) is curtailed, and that is precisely why this is a crisis. In this sense, crisis can also be said to loom over those who feel on the verge of losing either or both of these freedoms.

\section{How to distinguish}

knowledge ignorance uncertainty

I don't know.

By starting from the place of situated knowledge while listening to other knowledges, and abandoning the Western-centric, logo-centric epistemology. 


\section{Citizenship}

biopolitical

(naturalized) necropolitical

(after death on the soil)

\begin{abstract}
After Achille Mbembe, we recognize that in the era of global capitalism, there is never only biopolitics and biopower, but also necropolitics and necropower. The 'production' of death is an essential part of the capitalist apparatus.
\end{abstract}

The age of necropolitics is characterized by production and localization of the death-worlds where the whole populations are brought to the life in the condition of death and whole societies are reduced to the level of the 'living dead'. Necrocapitalism and necroeconomy produce and exploit this form of life on the verge of death. Although Achille Mbembe articulated this concept in order to explain the process in the context of third worlds, necropolitics today, also operates within the context of the first capitalist world. These relations are important to understand as they define the social, political and economic reality of the neoliberal global capitalism. In the First Capitalist World, there is a life with a style (biopolitics), and outside of the First Capitalist World, the process of necropolitics is happening, where death is the major regulator of life. However, it is crucial to understand that biopolitics and necropolitics are not separate processes, but quite the contrary that they are connected and together explain the complex contemporary power relations.

This becomes quite evident in the case of the treatment of refugees and asylum seekers at the EU borders, or as put forward by Marina Gržinić: "The new proposed measures to control the external borders of the Schengen agreement may be seen as those lines of division that will regulate the process and politics of death. Those who will be stopped at the EU frontier are already the living dead: those who have nothing to lose, not even life. The EU's improved and coordinated immigration policy is obsolete, as it is nothing more than a policy enabling the setting up of a system to select, reject, and ultimately kill" (Gržinić 2016, 39).

An example of necropolitical citizenship is connected to the Lampedusa shipwreck from 2013 when hundreds of migrants tragically drowned trying to reach the EU vial Italian island Lampedusa. In a cynical populist twist the recovered bodies of drowned migrants were proclaimed to be Italian citizens, i.e. granted Italian citizenship in their death. 
deathscapes

non-places

I cannot speak about this. It would be a philosophising intellectual position where from I would speak on the behalf of the dead and the victims, from purely speculative point of view. Like a philosopher who can make anything about his discourse. Death is not theoretical question.

Places of immobility, of "waiting in the limbo" in the zones between borders, at the wastelands of seas and desserts of anonymous deaths at the increasingly militarized borders of the first world (EU, US...) fortresses.

\title{
How to overcome the sense of impotence in the face of planetary capitalism?
}

\begin{abstract}
We should not be mobilized into the war machine the capitalism has created. This war machine is determined by the economy, agon and positions. Should we then create our own war machines? Should we create war at all or more agon and more positions? The war is always a crusade for something and against the Other. The planetary capitalism is necropower.
\end{abstract}

As the Hindi song I mentioned above asks "what has being human wrought?", I see a similar kind of impotence or paralysis induced by any crisis situation. To quote Shelley Sacks, "Sustainability without the 'I' sense is nonsense." Hence, my response would be to snap out of this impotence by realising ourselves as agents who are responsible. However, it is fruitful here to understand responsibility as response-ability, as developed by Sacks.

- Response-ability: Artist and social sculpture practitioner Shelley Sacks proposes responsibility not as imposed on us by an exterior law or God, but rather as stemming from our (inner) "ability to respond." Furthermore, to behave response-ably in a crisis situation can steer us away from paralysing ourselves in the shadow of the overwhelming "crisis" or "event" of the Refugee. It is in understanding this responsibility as response-ability (which differs from the responsibility that is thrust on us or that burdens us from without, e.g. that which is dispensed by the state, family, religion, etc.) that we can choose a course of action from myriad options. It is precisely in this choosing, that our freedom lies, which can itself be a strong motivator to act. Thus, failure/crisis seems to feed itself, because it is at the end that so many new possibilities can be born. 
- Warmth work: Some quotes which describe warmth work. These can be very valuable in approaching the kind of response that the event of the Refugee calls us to perform.

[t]he inner movement to shape a humane and ecologically viable world first occurs, warmth work can be understood as intensive, inner thought work, in which the activated and enlivened will engages with the thought of the heart. Such active, inner imaginative work is integral to entering 'the dynamic being of things' (another footnote) and to developing new organs of perception (footnote). (Sacks 2011, 88)

A phrase (terminus consciousness) I have borrowed from Declan McGonagle. It parallels Beuys' idea of crystalline, fossilised thought that needs to be overcome with the warmth work of negotiation and exchange, through forms like the "permanent conference" (96). "A phrase often used by Beuys to describe the new, connective forms of thought needed to overcome cold forms of rationalist thinking that seek unity in multiplicity by abstracting what is common from the parts. For both Goethe and Beuys, it is essential to understand the multiplicity in the unity. This active entry into the dynamic being of things is part of the 'warmth character of thought. (Ibid.)

- John Cage: John Cage's 4'33" can be seen as a performance philosophy that could be extended to the event of the refugee with respect to its invitation and freedom to listen (connected and similar to active listening outlined below). Cage invites the listener (and the performer) to experience freedom. The piece, originally provocative, "still demands a willingness of the listener and prompts him to think and reflect. Additionally, it also has the virtue of installing a way of listening that does not allow for jumping to conclusions, but that demands a quiet and simple listening to sounds. Could this way of listening be described as a susceptibility to the other, passive in its dedication to the sounds that present themselves, and active in its alertness to and preparedness for a diversity of acoustic events?" "The performance ought to make clear to the listener that the hearing of the piece is his own action-that the music, so to speak, is his rather than the composer's" (Cage in Gena and Brent, 22). With this comment, Cage gives more freedom to the listener, but also more responsibility. In its non-articulatedness 4'33" provides the listener (and the performer as well) with the freedom to add value and meaning (or none at all!) to the piece. It is the responsibility (response-ability) of the listener to assign meaning and sense to this music" (quoted in Cobussen 2002). Thus, listening with a sense and awareness of response-ability which opens us up to freedom can also be an example of how performance philosophy can organise, deliver and receive crisis and the event of the refugee.

- Agents of change: Response-ability and realising ourselves as an "agent" of change, i.e. contributing to a change rather than trying to change something big. This social sculpture practice (which has also been translated into performances in some previous projects and hence has the potential to become a performance in this situation of the refugee), can truly help one/us snap out of existential paralysis and contribute towards a political, social and economic transformation. 
How is philosophy of the refugee different

from philosophy of any other marginalized

group / (group of) people under threat?

Without objectifying the refugee?

I would say, that it would have to be non-philosophy. Here, I don't mean specifically the non-philosophy by François Laruelle, but any gestures of thought, which do not function philosophically. Then, it would mean thinking as practice, and as an immanent practice. There would be no 'questions' or 'topics' such as "What is a refugee?" I am not a refugee, but I am a Stranger, more than the Other. Laruelle proposes that we should practice 'victim-thinking', from the force-of-thought. Not to become a philosopher and not to become a victim, or refugee. So, we would have to stop regarding the refugee as an exception (Carl Schmitt), a deviant (Émile Durkheim), or the existential Stranger (Albert Camus). The persecution of the refugees is the foundation of humanism, it is the foundation of victim-thinking.

To turn these questions around we can ask: whose philosophy is the philosophy of the refugee? Can/does bare life philosophize?

What word(s) other than "refugee"?

Victim or a heretic.

\section{What word(s) other than "philosophy"?}

Non-philosophy or cloning. Politics.

To engage with questions of "philosophy" and "refugee" may be confounding, producing a series of critical failures (or failures in criticism): an inability to imagine the experience of another; an insufficiency of vocabulary that is already overdetermined by media discourse; an unwillingness to speak on behalf of others' experiences; a disjuncture between what everyone knows (these people do not deserve their horrors) and what everyone does (proclaim their helplessness to do anything about it).

These cards are intended to "un-block" critical thinking by undertaking conversations that begin with a collective choice between two alternatives, where the options are not straightforward binaries, and where the basis for making a choice is itself an area for discussion. As a tool for creative conversation they are directly inspired by artist Hamish MacPherson's How Many Things to Build the Future? (2007), an open-ended score for collaboration consisting of cards that contain pairs of words, instructions for collaboration, and a prompt for an intervention or reflection on that collaboration. 
mobility

or

security

unknowable

or

unsayable

transplant

or

translate

interstitial

or

institutional

crisis (krísis)

or

revelation (apokálypsis) underrepresented

or

overdetermined

refusee

or

refugee

repair

or

prepare

empathy

or

estrangement

no borders

or

no protections 
safe space

or

liminal space

illegal

or

illegible

democracy

or

insurgency

testimony

or

mimesis

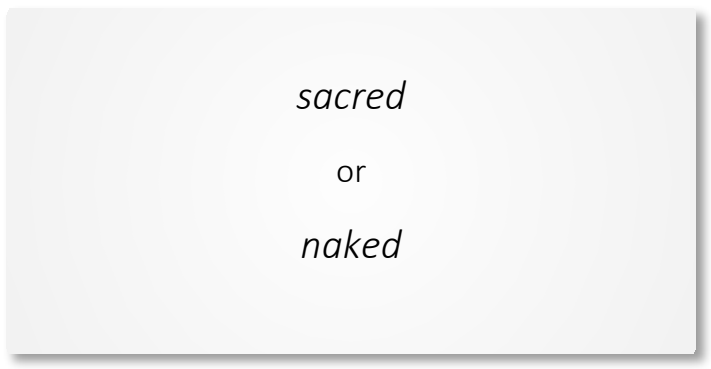

persona

or

stranger

no future

or

no past

civility

or

ethics

representation

or

surrogation

bones

or

breath 
Where I see "or," I feel a need to re-wire and re-think. As such, I started imagining a kind of epistemological choreography that commences through a strategic exchange of "as" for "or," like in the phrase "Bones as Breath" (modified from Theron's original Bones or Breath). This shift leads to short flights of thought:

Breath, the numinous, unseen vouchsafe of shared humanity, humanity being something more than bodies...but now, with Refugees, the breath is transmuted to bone, and these bones are lost at sea, and this loss is the unseen vouchsafe of a hierarchical humanity where those with the privilege of permanence count and those who live on the wind do not...

I think of this as choreography because the "as" moves my thought and frees it from its static stuckness. I am left with neither an argument nor a complete thought, but, instead, a tiny dynamism: Something about breath-that which we all sharetransmuted to bone and thus weighted down...

Here are a few more flights of fancy that are the results of other small dances in me:

Interstitial as institutional: What a dream! I'd like to teach there, at that institution

Crisis as revelation: Ah! Crisis is our mediality.

Persona as stranger: We do not know ourselves, only those parts we think we perform.

Democracy as insurgency: Viva Zapatista!

Civility as ethics: Sad, perhaps, that it has come to this, but we have an opportunity to act ethically by merely acting civilly.

Unsettling as demystifying: If we could see what is actually here in front of us, we would not be able to remain silent. 
How do we know how we truly feel, when "feeling" is mined for value and as political tool?

\section{"Philosopher in the Camp II" \\ (a musicalized "tango poem") \\ with music by Garlos Gardel}

A https://soundcloud.com/performancephilosophy/philosopher-in-the-camp-ii

Never mind I am persecuted

I could be dead, I seek no friendship

No tomorrow and no abode.

I came here, I knew l'd find you

The camp was always here

Awaiting for me, from the moment

You left this land to win the World.

I am colonized, that makes me a criminal

And the camp, you left it empty

At all costs you looked away

While I moved in to see what it is like

To arrive sans passport et sans rights

My journey is a mere ritual

of return to something lost.

I stir up history, I feel rude

When I laugh at your friendship

Because I found myself

As your potential enemy

Your envy is my triumph

As I explore my jungle

I also see you, observe your habits:

In you comfort I see loss.

Leaving it all to a few,

who will multiply the bread,

with money... god knows how.

And all along you have been dreaming of the camp

A "place" where history could be dumped

Because you figured it was mud

Or so you thought. 
And the world became meaningless

In the desert of your comfort

It was only you and the camp

That you dreamed as an unreal

abstract space, a simulacrum

of two dimensional zombies

and apocalyptic fantasies.

I tell you the camp is real

With more landscapes that your video games

I bring it to you as a gift:

A Trojan horse, a Pandora's box

The world is a camp my dear

And history in it ferments

And revives like compost.

To the leftovers of your cities

I invite you to move in

No such thing as calculation.

This is not a place one goes to

This is not home, and home is never

Where one goes to anyway.

Leave your tired Humanity

Because it is insulting

To feel so lonely and unique

In the universe.

My friend, a criminal you are not

but a refugee invited

to the ghetto of the World.

Music recorded live with Nacho Gonzalez on guitar and Naseem Alatrash

on cello (Berklee Internet Radio Network, 2015.

https://www.youtube.com/watch?v=nEGJeUTAVKw) .

(I philosophize, therefore I am.) 


\section{Can you specify the relationship between death production and a refugee?}

At the agriculture industry in the region of Almería in Andalusía the large number of the workers who are doing the boring and tedious labour at the 'plasticulture' - the greenhouses-are from North-Africa or Sub-Saharan countries. The majority of them has arrived there without papers. Large number of the workers are also illiterate or at least have no understanding how the employers are obliged to follow the collective agreement based on the European and Spanish law. They are refugees or illegal immigrants crudely exploited, also for the reason that there is an excess of labour for the employer to select his workers. Some of the workers live in the huts build from the same plastic than the greenhouses, and they live within the same area of the greenhouses. It is a 'camp' not for refugees, but for the cheap labour. The relationship is between the production of strawberries, melons, zucchini, etc., and the production of agonizing conditions for the immigrant workers and in the end, production of death. The food is produced by the potentially dead labour.

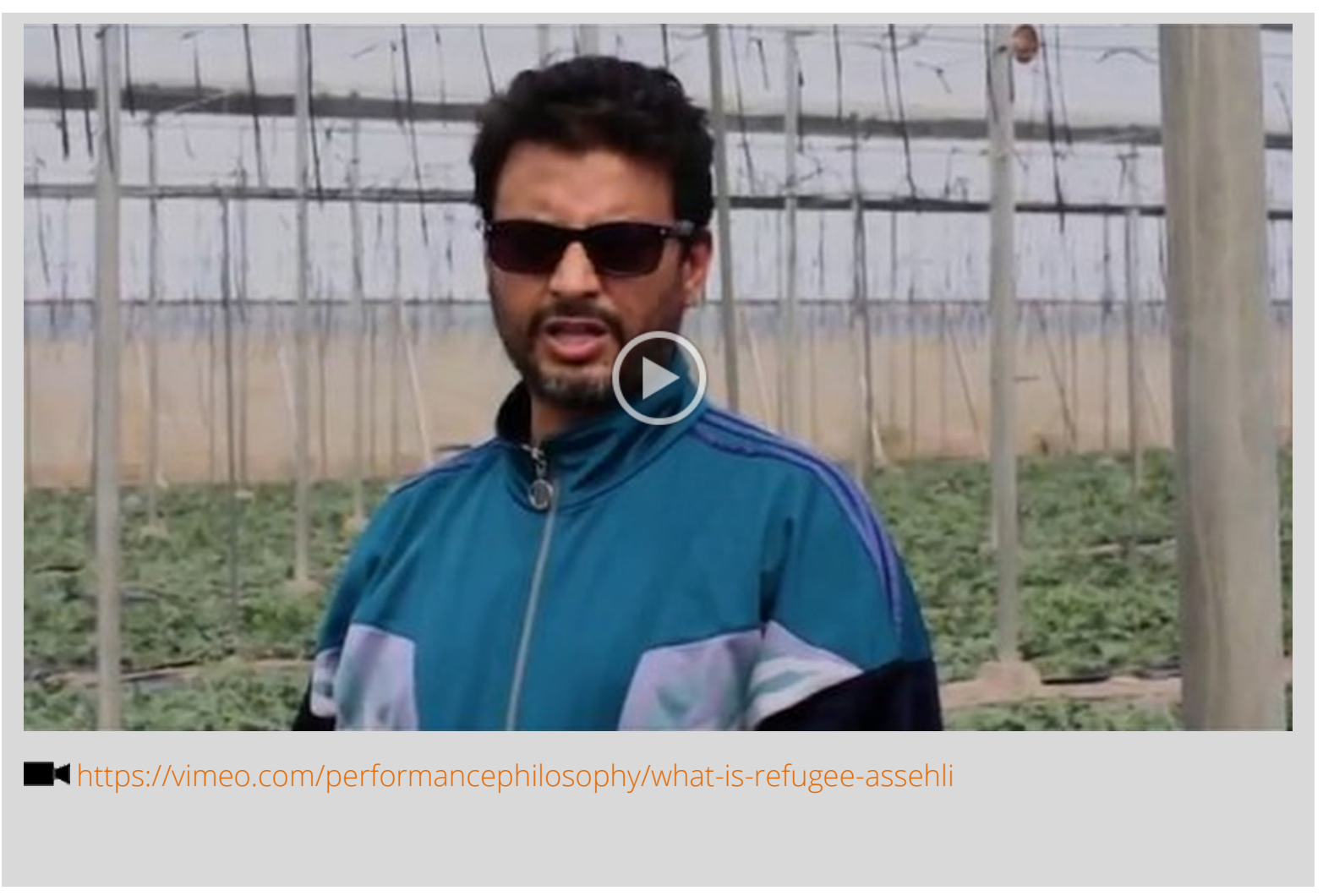




\section{Can the right to mobility be put \\ forward as an immanent force \\ (political) for the refugee?}

While developing a new definition of "new cosmopolitanism," I have decided to adopt Étienne Balibar's "right for circulation," or right for global movement, as one of the fundamental human rights and as the basis of nomadic or cosmopolitan citizenship. "To ask whether a nomadic citizenship, being at the same time a mobile or traveling citizenship and a citizenship for the travelers, is thinkable [...] means to ask how the ageold figure of the citizen could be reconfigured in the age of global migrations, and if it proves inevitable, how it could also become an institutional reality" $(2011,207)$. Balibar identifies four characteristics of nomadic citizenship: "1. The right for circulation or movement; 2. anthropological effects and ontological paradoxes of globalization; 3. antagonistic tendencies of (de)terrorization; and 4. The instruments of enlargement

Right to mobility is unfortunately precisely what is denied to refugees. For example, when refugees are fingerprinted at the borders of fortress EU, their bodies are immobilized because of the speed of this digital information, which is at once, in a matter of seconds sent to all the border crossings inside Europe. Moreover by the act of fingerprinting the border becomes (digitally) inscribed into the body, thus rendering it immobile / deportable. of the right of circulation and its political recognition." In this context, the right for circulation can be recognized as "an immanent force (political) for the refugee" as well as a right for unconditional hospitality as articulated by Derrida (Derrida and Dufourmantelle 2000); and further in the context of refugee crisis and rising nationalist movements, the right to mobility becomes a political force for each individual and a call for responsibility as well as an issue of hospitality on the part of the nation state.

It was Hannah Arendt, who suggested that after the World War II, our view of the world must drastically change ([1943] 1994). The figure of a refugee must now be hold in the centre of political philosophy, economics and state's functioning. Agamben 2000), Derrida (and Dufourmantelle 2000), and Appiah (1997) similarly argued, after Arendt, for recognizing the right for mobility, the right for seeking refuge and settlement as a new social order and political imperative to be adopted by the nation states. In this imperative, cosmopolitanism provides the dictum of acceptance. It opposes the paradigm of stranger-danger (Ahmed 2000) and it becomes a motion for dialogue, the only model of contemporary life that could aid us in dealing with the outcomes of mass migration and rising nationalistic xenophobia.

Following Arendt's analysis of the psychologically degrading power of being a refugee (1994, 119), Agamben suggests

the refugee is perhaps the only thinkable figure for the people of our time and the only category in which one may see today - at least until the process of dissolution of the nation-state and of its sovereignty has achieved full completion-the forms and limits of a coming political community. It is even possible that, if we want to be 
equal to the absolutely new tasks ahead, we will have to abandon decidedly, without reservation, the fundamental concepts through which we have so far represented the subjects of the political (Man, the Citizen and its rights, but also the sovereign people, the worker, and so forth) and build our political philosophy anew starting from the one and only figure of the refugee. $(2000,90)$

In his plea, Agamben is concerned with de-valuing of the so called "naked life", our preference to thinking of people as citizens. He traces the origins of this dangerous distinction back to the Declaration of Human Rights, in which naked life "comes to the forefront in the management of the state and becomes, so to speak, its earthly foundation" (93). A refugee, stripped of his/her rights as a citizen, presents the essence of this naked life; and so, as Agamben insists the right of movement and asylum "must no longer be considered as the conceptual category in which to inscribe the phenomenon of refugees. [...] The refugee should be considered for what it is, namely, nothing less than a limit-concept that at once brings a radical crisis to the principles of the nationstate and clears the way for a renewal of categories that can no longer be delayed" (94). When it comes to the foundations of a new democratic state, Agamben's political recipe consists of rethinking Europe (as his example of such a state) as

an aterritorial or extraterritorial space in which all the (citizen and noncitizen) residents of the European states would be in a position of exodus or refuge; the status of European would then mean the being-in-exodus of the citizen (a condition that obviously could also be one of immobility). European space would thus mark an irreducible difference between birth [nascita] and nation in which the old concept of people (which, as is well known, is always a minority) could again find a political meaning, thus decidedly opposing itself to the concept of nation (which has so far unduly usurped it). This space would coincide neither with any of the homogeneous national territories nor with their topographical sum, but would rather act on them by articulating and perforating them topologically as in the Klein bottle or in the Möbius strip, where exterior and interior in-determine each other. In this new space, European cities would rediscover their ancient vocation of cities of the world by entering into a relation of reciprocal extraterritoriality. (95)

In this argument, Agamben makes a philosophical leap impossible to achieve through the logic of immobility or settlement, and so he proposes to consider movement as one of the basic human rights and hence the driving force for rethinking of the foundations and functions of the nation state.
How would this question relate with the labour market in Europe, that would not only exploit the refugees? What would guarantee that the refugee, who would become an immigrant worker, would not be exploited in the labour market in sweatshop conditions? Why the production of death in Sub-Saharan countries exist in the first place, or what is the significance of it to the global economy? The situation in the farms mentioned above is different for the Polish or Romanian workers in the Andalusía. They have a citizenship from an EU nation, and they have more place to argue better conditions for work and to live for themselves. How can we guarantee that the immigrants from SubSaharan Africa would not become the janitors of Europe? How can we resist the philosophy

of capitalism, economy and agon, which is the determination in the last instance of global capitalism? 
Kwame Anthony Appiah offers a further thought on the right of mobility: in his advocacy of "rooted cosmopolitanism" or "cosmopolitan patriotism", Kwame Anthony Appiah cites Gertrude Stein's famous saying: "America is my country, and Paris is my hometown" (quoted in Appiah 1997, 618). This saying helps Appiah to articulate the view of mobility as a foundation for the new philosophy of cosmopolitanism, in which the idea of a cosmopolitan citizen who belongs to the human community is concretized through this citizen's willingness to take interest in the lives, practices and beliefs of others. According to Appiah, "cosmopolitanism begins with conversation across boundaries", and so he "encourages us to embrace both local and universal loyalties and allegiances and denies that they necessarily come into conflict with each other" (Seifikar 2008, 307-308).

Jacques Derrida has articulated this position of cosmopolitan dividedness as the "politics of exodus" (1984, 120), which can serve as "a subversion of fixed assumptions and a privileging of disorder." This politics is rooted in the simultaneity of inbetweenness, the cosmopolitan imperative to "gesture in opposite directions at the same time: on one hand to preserve the distance and suspicion with regard to the official political codes governing the reality; on the other, to intervene here and now in a practical manner and engage whenever the necessity arises. The position of dual allegiance, in which I personally find myself, is one of perpetual uneasiness" (ibid.). Such position might be strictly personal to Derrida, but it is shared by other philosophers of displacement, including Edward Said, Julia Kristeva or Helen Cixous, who have experienced the rupture of dislocation themselves. The politics of cosmopolitanism as Derrida would show himself, spills into the cosmopolitan artist's aesthetics. Thus, in responding to the questions about the tension between the politics of exodus and the work of deconstruction, Derrida said: "I try where I can to act politically while recognizing that such action remains incommensurate with my intellectual project of deconstruction" (121). "Deconstruction is always deeply concerned with the 'other' of language. [...] the critique of logocentrism is above all else the search for the 'other' and 'the other of language"' (123). In this discourse, the other is beyond language, it is "not a referent in the normal sense that linguists have attached to the term" (124); it is a production of meaning through the work of distancing and difference (125).

But the pleasure of encounter goes beyond an intellectual exchange of ideas, it becomes experiential and sensual, the process where the cosmopolitan encounter is located as well. Today's cosmopolitanism is equally rooted in the tendencies of localization as nationalism and globalization as (in)voluntarily re- settlement of masses, as well as in the individual practices of exile, economic migration, nomadism, and personal post- exilic heritage. Hence, it re-enforces a responsibility of a politically aware artist for taking a moral, ethical, and political stand. It often is manifested as the artist's world view and/or personal philosophy; their pointed look at the conditions of migration and refugee crisis, their questioning the impact theatre and performance arts can make today.

\section{Performing philosophy. Estrangement as a form of empathy. Dancing with strangers-tango...}




\section{How to distinguish}

capital labour play

Mohammed is from Rif, Morocco. He has been working at the plasticultures for seven years. He is not illegal immigrant anymore, but he does not have the permanent work permit, which would allow him to look for job somewhere else in Spain or Europe. His employer is deliberately not giving him long enough contracts, which would entitle him to receive this permit. The wife of Mohammed, Fatima works on the same plasticulture. They don't like the work, where the workday may easily be prolonged over eight hours if an emergent order arrives. In the summertime, the temperature in the plastic house rise to 80 degrees Celsius. Fatima worked until the eighth month of her pregnancy, just like anybody else. They have four children and they live in a concrete building, that is just beside the plasticulture compound. Their son Younes cannot play football at the nearby field after dark, because at one night he was beaten by some racist thugs. He is fourteen years old, and he would like to become a professional sportsman. He also wants to move to north, to Basque country, which is not that hostile to Moroccans, so they say. Every evening they sit at home, because of the fear of racist attacks. The capital in this picture is the house, which they rent from the owner of the plasticulture farm. The labour they do in the plasticulture, will never allow them to gain so much money that they could save for property. Any playtime is away from the possible gained position. To have children is not a choice. It is self-evident, and it is self-evidently also a capital, a possibility. After they have joined the Soc-Sat worker's syndicate in Andalusía they have faced difficulties with keeping the job. But through meeting with other people, they have understood the relationship between capital, exploitation of labour and their possibilities in life.

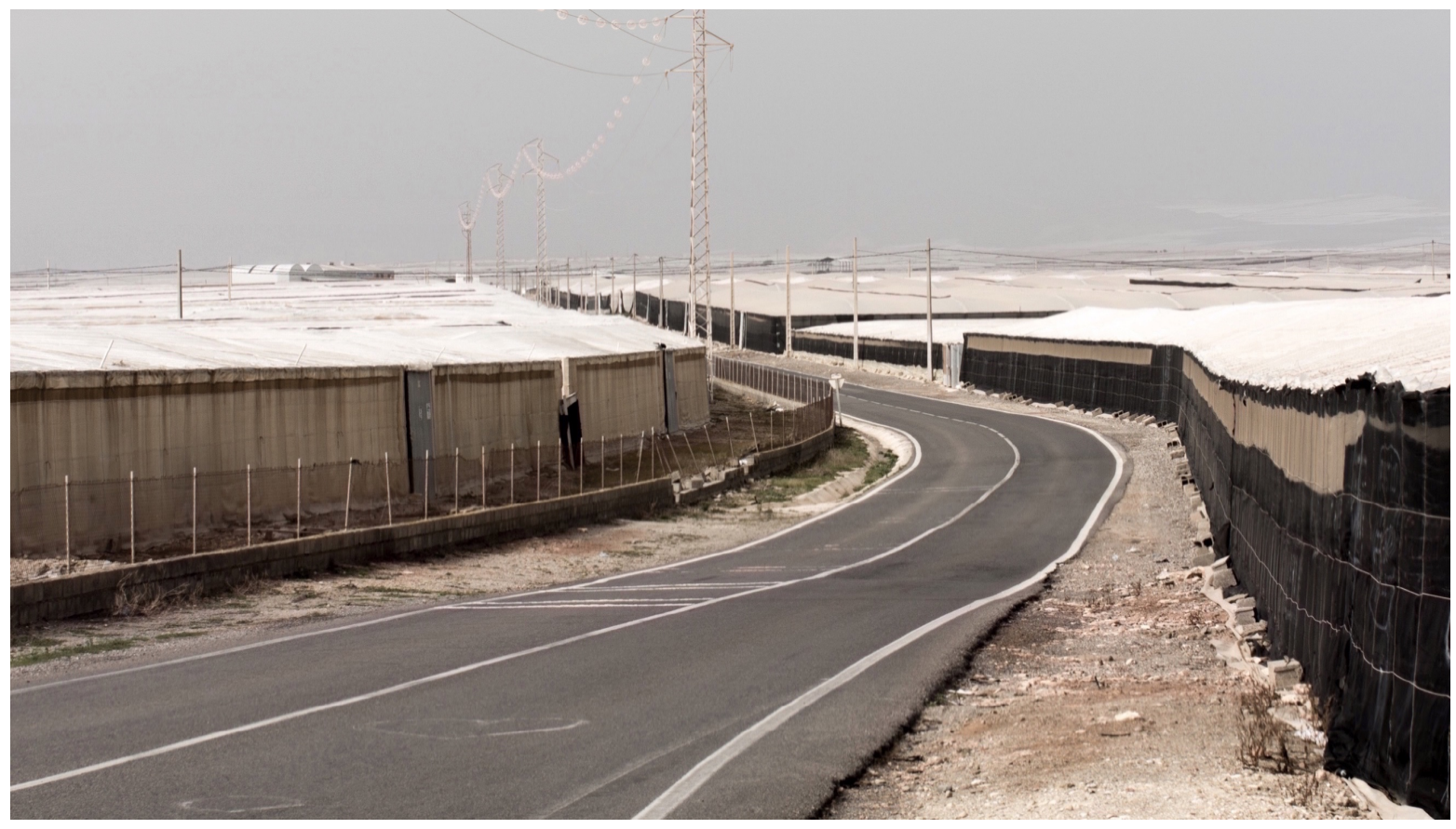




\begin{tabular}{ccc}
\multicolumn{3}{c}{ How to distinguish } \\
philosophy & belief & dox \\
science & religion & common \\
art & spirituality & knowledge
\end{tabular}

How do you address the relationship between

overflow as the economic apparatus, or a model, and refugee, migrant worker, or asylum seeker?

The overflow is a necessary part of the production of value. It is axiomatic where each factor such as the refugee or worker has a potential. The value of each factor is never zero or below zero, but the value is infinitely decreasing towards zero. Following the necropolitical paradigm even death has a value, until a body has become pure matter-which in turn follows another parameter of value.

How does a post-nation world look like?

On one hand it looks like that the neoliberal form of capitalism aims to dismantle nations into different economic zones, as it is now for the European Union. How can we distinguish the neoliberal assemblage of economic zones in terms of the need for Universal Basic Income, for instance? We need to dismantle the Nation States as the creations based on identities, but how to do this, when the neoliberal transformation dismantles the nations into zones of competence, agon and cooperative enterprises of noopolitics? The economy is the decisional operation of the noopolitics in practice. The crisis is a mandatory practice determined in the last instance of the economy.

(handwritten working notes:)

\begin{abstract}
international global
\end{abstract}
artistic nation
NSK, El glob
Quebec

lst nations

bolo'bolo sci fi

Christiania e.g. Somalia Venezuela something Palestine 


\section{IMAGES}

\section{Humane}

\section{Human}

\section{Hunger}

\section{Honour}

\section{Happiness}

\section{Heat (warmth)}

\section{IMAGES}

Intended to shock, visual images of 'third-world' suffering in Western media_of the dead, wounded, starving — constitute generic decontextualized horrors that elicit pity and sympathy, not discernment and assessment. As Rey Chow (2006) has argued, Americans have increasingly come to know the world as a target: when wars break out, foreign areas and peoples briefly enter American mainstream public discourses, often via deeply disturbing images of suffering, as embodiments of (naturalized) violence, crisis, and disasters (Fernandes 2013, 193). The hyperfocus on suffering, and the outpouring of outrage and concern over dead and injured refugees, has become a substitute for serious analysis of the geopolitical conditions that produced their displacement in the first instance. Constructed for Western consumption, these spectacular(ized) images render invisible and inaudible displaced people's everyday and out-of-sight struggles as well as their triumphs as they manage war's impact on their lives (Lubkemann 2008, 36; Hyndman 2010).

\section{IMAGES}

\section{Borders}

Brave

\section{Bombs}

\section{IMAGES}


How does the interstitial flow?

\section{How to distinguish}

home away unsure

The victim thinking has never had a

home. It is radically immanent practice.

\section{How to distinguish}

enemy

neutral

We need to think what the Stranger or victimthinking is, where the Stranger and human is without a universal consistency. How to create a non-philosophical practice alongside the postulation by François Laruelle, where the victim is the "last point of view on history" $(2011,34)$.

\section{Bare life}

Precarious life

Disposable life

Mere life

After life

improper life

And 'lived' without a life, in other words, performing living without the transcendental concept of life.

(am schlafen speak?) 
How to think as determined by the $\mathrm{X}$, which does not appear at all, remains to be nonrepresented, and not even a shadow?

The function of the Other is a reduction of the $\mathrm{X}$ into a position of a deviant from the norm, which is defined by the universally accepted (katholikos) and the proper (orthodoxos) thought. The community of the proper and the universal thought must define the victim=X as a position or a sufficient identity of the Other. Thus, the axiomatic X is not only a placeholder for the Other in the dualist calculation, but the axiomatic $\mathrm{X}$ is a function that performs without a subjectivity or signified identity. The Other is already a concept-it is a postulation for metaphysical problems that exist. The Other has potentiality, possibility, duration and existence, whereas the axiomatic $\mathrm{X}$ is a function. It would be a mistake to conflate the Other and the $\mathrm{X}$ together, and search for the 'Othering' as a replacement for the axiomatic X. In other words, subjectification will not cease the axiomatic function of the X. They are from the two different registers, with different functions. The Other $\neq \mathbf{X}$. The Other is a particle of a dual system, whereas the $\mathrm{X}$ is a complex number. The concept of the Other acquires meaning from a discourse, but the $X$ is merely a function. In the logbook of a slave ship, the X may have stood for the indeterminate amount of loss of cargo, i.e. humans as slaves. The X does not signify a face, but only a body, in other words, it is a thing or matter. The X may also signify slavery itself, for instance in the performative of rejecting the last name inherited from the slave owners by Malcolm X. The X may have a radical function, but it is hardly an alterity.

Is it possible to make fragility a general, social value?

\author{
(Handwritten notes:) \\ tragic - comic - romance \\ jokester \\ resilience / rigid male \\ female
}

\title{
How to distinguish
}

safe

at risk unsettled 
Can naming things clearly do performance philosophy?

Can there be a performance of unnaming?

Discargo: Uberoverundunder

口uttps://vimeo.com/121857166

The artist Michael Murphy, known for his series of what I think of as parallax sculptures, has created a piece called Identity Crisis. From one position, we (i.e., you, I, other observers) perceive an outline of the continental United States. Looking closely we notice that the appearance of the continent comes into being thanks to carefully placed objects hanging from the ceiling. In turn, these objects reveal themselves to be fire arms, most of which are automatic assault weapons. We are looking at a representation of the United States made from guns.

If we start to walk to the right, a shift occurs. The predominant composite image of the United States falls apart and the individual guns take focus. There must be at least 100 weapons. All of them are predominately black. Some silver accents gleam in the gallery lights. They are all hanging there harmlessly. But as we continue on our slow walk, the individual guns collude once again in the production of another representation. This one is a giant handgun. The giant gun, made of many smaller guns, aims to the left, back to where we once stood to view the United States.

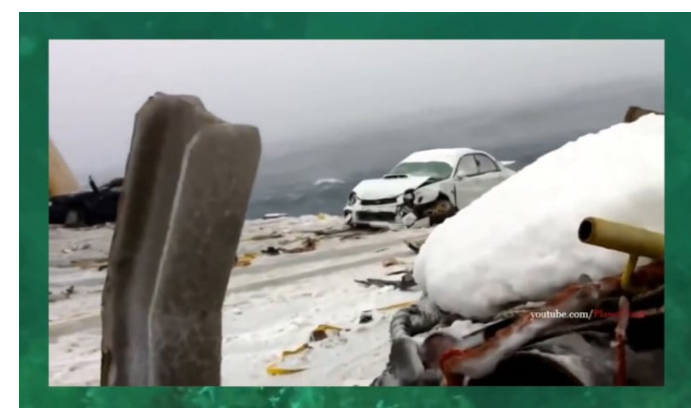

Music by Chrys Bocast. Video montage by Jon McKenzie.

To rethink overflow through the refugee, let us start with a highly charged philosopheme of "over": Nietzsche's Übermensch, and pose refugee as Übermensch: not as Aryan superman but under-man or under-human, the dispossessed and migrant, the ones who go overboard in going under: under the border, under the fence, under the ground, under the water, over and under all the overseers, political checkpoints, and conceptual markers of belonging and non-belonging.

If we understand refugees as those seeking shelter but also experiencing the intensity of flight, we find the strangely embodied $\mathrm{im} / \mathrm{mobility}$ of going under: the refugee's flight for and from shelter after shelter and the shelter of and from flight after flight. An unsettling intensity of settling, a mobile immobility and immobile mobility. Bodies swaying here in hopes of staying there and swaying there in despair of staying here. Going somewhere while going nowhere and vice versa. Going over and under, over and over: the refugee goes Uberoverundunder, overundover. 
Now we understand the title of the artwork. The identity of the United States is torn between, on the one hand, its status as a geopolity housing a democratic government predicated upon the liberty of each and every one of its citizens, and, on the other hand, its violent day-to-day killings of men, women, and children at the hands of civilians and law enforcement officials alike. The United States is a country of guns and therefore a country of murder and suicide. It is a divided nation, split internally between fear of the other and the militant defense of private property.

Murphy's artwork compels me to think of a parallel representational scheme for the refugee where the parallax vision would reveal not the identity crisis of the United States but the inner tension of the figure "Refugee." Who is this figure we read about so much in newspapers and social media feeds?

Does "refugee" have a foundational identity, or must we draw instead upon philosophies of difference to prescribe an array of subject positions to this figure? What composite image would greet the observer from the starting position of a Murphy-like parallax sculpture of refugee? In the place of guns, what objects would function as the atoms of this larger image? What thoughts would come during the transit from the first position to the final position? And what image would act as the antipode to the starting scene? By working through these thoughts and creating an imaginary counterpart to Murphy's Identity Crisis, might we be able to discern the complexities of the particular "identity crisis" summoned by the singular "Refugee"?

Here's what I see. The starting image is a representation of the dead body of threeyear-old Alan Kurdi who drowned along with his older brother Ghalib and his mother Rihanna on September 2, 2015 as they fled war-torn Syria via Turkey. The particular identity of this child challenges you to abandon the general noun "Refugee" and seek out the name of each person who is made to belong to that group. In the words of Seyla Benhabib, this image assists in imagining the refugee as concrete other. 
The composite image of Alan arises from many dangling rafts, referencing the treacherous mode of conveyance utilized by those seeking to cross the Mediterranean. Unlike Murphy's Identity Crisis, however, where approximately 100 guns make up the sculpture, the scale of this imagined work of art would necessitate at least 15,000 tiny boats. That number brushes up against a loose estimate of the lives lost crossing the Mediterranean since Alan Kurdi's death. The optical effect that results from focusing on an individual hanging raft and then refocusing to take in the totality of hanging rafts causes a mild case of vertigo, not unlike the dizziness that results from reading one report after another of the deaths and rescue operations taking place in the Mediterranean.

As you continue walking, the rafts begin to coalesce into the final image, that of an aleph. The aleph functions here as the antipode to the particularity of Alan Kurdi. As a citation of the set theory of Georg Cantor, the aleph enables your mind to make computations with figures that seem too big to count. How do you conceptualize the $65,000,000$ people currently dislocated form their homes across the globe? How do you design, propose, and then enact political changes capable of providing those $65,000,000$ people with a life worth living? It is not impossible to do such things, but we need to overcome the stultification that comes from the encounter with many millions of suffering people. The aleph of set theory might help us with our displaced-persons calculus. Second, the aleph conjures the story of the same name

In his story, Borges presents us with two Alephs: the first one is platonic, offering us the "complete" mirror vision of our personal obsession (Borges' love for Beatriz), particularly the one that seems to slip away from us (in Borges's grieving). The other Aleph (or the "X"?, see Nauha) is the one that confronts us with the paradox of our own humanity, one that exists because it does not seem to exist (in the interior of a column of a Mosque in Cairo). The "crisis" of the refugee may be a confrontation with the radical nature of this paradox, where our own humanity is denied (actually and symbolically), and a human leap of faith (for existing) is being resisted (passive/active point of tension) because of our limiting obsession with a "complete" vision. by Borges and the quasi-mystical vision that unfolds for the story's narrator. Such a vision, one that encapsulates the Everything of the world can translate in this sculpture into a prophetic vision of radical alterity through which a kind of Levinasian politics of the other comes into view.

The identity of the "refugee" is not contained in either the pole of the aleph or the pole of Alan Kurdi but, rather, in the crisis of emotional and epistemological instability that comes from traversing both poles of this imagined sculpture. We move from an affective encounter with the death of a child, through a dizzying array of tiny plastic boats, to the epistemological encounter with infinite sets and mystical visions. Somewhere in there we determine what else "refugee" might be besides a statistic, a sad story, a crisis, or an unsolvable paradox of the contemporary moment. 
${ }^{1}$ As the character Frank Stokes (played by George Clooney) states in The Monuments Men (2014): "You can wipe out an entire generation, you can burn their homes to the ground and somehow they'll still find their way back. But if you destroy their history, you destroy their achievements (art and culture) and it's as if they never existed. That's what Hitler (IS?) wants and that's exactly what we are fighting for." (Additions in italics to adopt the quote to the current refugee crisis in Europe).

\section{Works Cited}

Agamben, Giorgio. 2000. "Beyond Human Rights." In Means Without End: Notes on Politics. Translated by Vincenzo Binetti and Cesare Casarino, 15-28. Minneapolis: University of Minnesota Press.

Ahmed, Sarah. 2000. Strange Encounters: Embodied Others in Post-Coloniality. London and New York: Routledge.

Appiah, Kwame Anthony. 1997. "Cosmopolitan Patriots." Critical Inquiry 23 (3): 617-639. https://doi.org/10.1086/448846

Arendt, Hannah. [1943] 1994. "We Refugees." In Altogether Elsewhere: Writers on Exile. Edited by Marc Robinson, 110-120. Boston: Faber and Faber.

Balibar, Étienne. 2011. "Toward a Diasporic Citizen? From Internationalism to Cosmopolitics." In The Creolization of Theory. Edited by Françoise Lionnet and Shu-mei Shih, 207-225. Durham, NC: Duke University Press. https://doi.org/10.1215/9780822393320-009

Cage, John. 1983. In A John Cage Reader: In Celebration of His Seventieth Birthday. Edited by Peter Gena and Jonathan Brent, 1-25. New York: C. F. Peters.

Cobussen, Marcel. 2002. Deconstruction in Music. http://www.deconstruction-in-music.com/navbar/index.html . Accessed 5 August 2018.

Derrida, Jacques. 1984. "Deconstruction and the Other: Dialogue with Derrida." In Dialogue with Contemporary Continental Thinkers: The Phenomenological Heritage. Edited by Richard Kearney, 139-156. Manchester: Manchester University Press.

Derrida, Jacques, and Anne Dufourmantelle. 2000. Of Hospitality. Translated by Rachel Bowlby. Stanford, CA: Stanford University Press.

Espiritu, Yến Lê, and Lan Duong. 2018. "Feminist Refugee Epistemology: Reading Displacement in Vietnamese and Syrian Refugee Art." Signs: Journal of Women in Culture and Society 43 (3): 587-615. https://doi.org/10.1086/695300

Gržinić, Marina. 2016. "Necropolitics and Global Capitalism." In The Crisis in the Humanities: Transdisciplinary Solutions. Edited by Žarko Cvejić, Andrija Filipović, and Ana Petrov, 39-45. Newcastle upon Tyne, UK: Cambridge Scholars Press.

Laruelle, François. 2011. Future Christ: A Lesson in Heresy. Translated by Anthony Paul Smith. London: Continuum.

MacPherson, Hamish. [2007] 2016. "How Many Things to Build the Future?" https://hamishmacpherson.co.uk/How-Many-Things-to-Build-The-Future. Accessed 5 August 2018.

Sacks, Shelly. 2011. "Social Sculpture and New Organs of Perception: New practices and new pedagogy for a humane and ecologically viable future." In Beuysian Legacies in Ireland and Beyond: Art, Culture and Politics. European Studies in Culture and Policy. Edited by Christa-Maria Lerm Hayes, 80-98. Münster: LIT Verlag.

Seifikar, Mohammad Hossein. 2008. [Review] "Kwame Anthony Appiah, 2006, Cosmopolitanism: Ethics in a world of strangers." Quest: An African Journal of Philosophy 21: 307-314. 


\section{Biographies}

Will Daddario is the author of Baroque, Venice, Theatre, Philosophy (Palgrave 2017), and co-editor of two anthologies: Adorno and Performance and Manifesto Now! Instructions for Performance, Philosophy, Politics. He is also co-editor of the Performance Philosophy Book Series (with Palgrave) and an original core convener of Performance Philosophy.

An empathy researcher and social sculpture practitioner with Gurukul dance training, Janhavi Dhamankar currently extends her performance-audience empathy via Performance Philosophy to integration of minorities in her PhD. She has performed, presented, and conducted workshops in numerous dance festivals, international conferences, schools, and residencies. She worked as editor for Pune Biennale 2017 and production assistant for One World Bearing Witness.

Milton Loayza is Visiting Assistant Professor at the State University of New York at Oswego. His research interests are performance and philosophy, Latin American theatre, eco-criticism, and artivism. As a performer he has recently appeared in multiple opera productions of Maria of Buenos Aires.

Jon McKenzie is Dean's Fellow for Media and Design and Visiting Professor of English at Cornell University. Author of Perform or Else: From Discipline to Performance, he is former director of DesignLab and co-founder of the media performance group McKenzie Stojnić. His work can be found at labster8. net and mckenziestojnic.org.

Yana Meerzon teaches at the Department of Théâtre, University of Ottawa. She has widely published on the issues of Théâtre and migration with Palgrave and Routledge. Currently she is working on several projects with Playwrights Canada Press and Modern Drama. Her new manuscript is under contract with Palgrave.

Tero Nauha is an artist and a postdoctoral fellow at the Academy of Finland funded postdoctoral research project, 'How To Do Things With Performance?' In 2015, he published his first fiction novel, Heresy \& Provocation. He has presented his performance art projects internationally. teronauha.com

Aneta Stojnić, PhD, is a performance and media theorist, artist, curator, and therapist. Currently she is a candidate at the Institute for Psychoanalytic Training and Research in New York. She has published three books and numerous articles on contemporary art, media, and culture. She is a co-founder of McKenzie Stojnić media and performance group (mckenziestojnic.org). anetastojnic.wordpress.com

Theron Schmidt is a writer, teacher, and artist, currently living and working on unceded Gadigal land. He has published widely on contemporary theatre and performance, participatory art practices, and politically engaged performance. He is a founding co-convener of the Performance Philosophy network and co-editor of this journal. He is also a frequent contributor and editorial board member for Performance Research, and editor of Contemporary Theatre Review's online Interventions (contemporarytheatrereview.org).

(c) 2018 Will Daddario, Janhavi Dhamankar, Milton Loayza, Jon McKenzie, Yana Meerzon, Tero Nauha, Theron Schmidt, Aneta Stojnić

Except where otherwise noted, this work is licensed under a Creative Commons Attribution-

NonCommercial-ShareAlike 4.0 International License. 